\title{
Expression \\ of the Medicago truncatula DMI2 Gene Suggests Roles of the Symbiotic Nodulation Receptor Kinase in Nodules and During Early Nodule Development
}

\author{
Anne Bersoult, ${ }^{1}$ Sylvie Camut, ${ }^{1}$ Ariana Perhald, ${ }^{2}$ Attila Kereszt, ${ }^{2}$ György B. Kiss, ${ }^{2}$ and \\ Julie V. Cullimore ${ }^{1}$ \\ ${ }^{1}$ Laboratoire des Interactions Plantes-Microorganismes, CNRS-INRA, BP52627, 31326 Castanet-Tolosan Cedex, France; \\ ${ }^{2}$ Institute of Genetics, Biological Research Center of the Hungarian Academy of Sciences, H-6701 Szeged, PO Box 521 , \\ Hungary
}

Submitted 20 September 2004. Accepted 19 April 2005.

\begin{abstract}
The Medicago truncatula DMI2 gene encodes a receptorlike kinase required for establishing root endosymbioses. The DMI2 gene was shown to be expressed much more highly in roots and nodules than in leaves and stems. In roots, its expression was not altered by nitrogen starvation or treatment with lipochitooligosaccharidic Nod factors. Moreover, the DMI2 mRNA abundance in roots of the $n f p$, dmil, dmi3, nsp1, nsp2, and hcl symbiotic mutants was similar to the wild type, whereas lower levels in some $d m i 2$ mutants could be explained by regulation by the nonsense-mediated decay, RNA surveillance mechanism. Using pDMI2::GUS fusions, the expression of $D M I 2$ in roots appeared to be localized primarily in the cortical and epidermal cells of the younger, lateral roots and was not observed in the root apices. Following inoculation with Sinorhizobium meliloti, the DMI2 gene was induced in the nodule primordia, before penetration by the infection threads. No increased expression was seen in lateral-root primordia. In nodules, expression was observed primarily in a few cell layers of the preinfection zone. These results are consistent with the DMI2 gene mediating Nod factor perception and transduction leading to rhizobial infection, not only in root epidermal cells but also during nodule development.
\end{abstract}

Additional keywords: legume-rhizobia (LR) symbiosis.

The legume-rhizobia (LR) symbiosis is characterized by the production of nodules on the roots of the plant in which the bacteria fix dinitrogen in exchange for nutrients derived essentially from the plants' ability to fix carbon dioxide. This mutualistic symbiosis is important not only because of its tremendous agricultural and ecological value but also because of its interest for studies of plant organogenesis, signaling, and plant-microbe interactions (Albrecht et al. 1999; Kistner and Parniske 2002; Limpens and Bisseling 2003).

The LR symbiosis generally is initiated in a region close to the root tips where root hairs are developing, called the susceptible zone (Caetano-Anollés and Gresshoff 1991). Effective nodulation requires two interlinked processes, nodule organogenesis and infection. Nodule organogenesis is initiated through cell divisions in the cortex and pericycle which lead to the

Corresponding author: J. V. Cullimore; E-mail: cullimor@toulouse.inra.fr formation of the nodule primordium. This process is initiated earlier than infection, which generally occurs through curled root hairs followed by the production of infection threads which route the bacteria toward the developing primordium. Infection of the primordium leads to formation of a meristem from which the nodule develops. The nodule is a veritable organ with a defined ontogeny and function. Genera such as Medicago, Trifolium, and Pisum form indeterminate nodules in which the meristem is apical and persistent, leading to a gradation of cells of increasing age and developmental status from the nodule meristem to the root. Nodulation is associated with the expression of specific genes that are induced in nodules compared with roots (nodulin genes). Studies of early nodulin $(E N O D)$ genes have shown that they can be used as markers of both early stages of nodulation and different developmental stages in the nodule (Albrecht et al. 1999).

Genetic analysis has revealed that the establishment of the LR symbiosis depends on the production of a specific rhizobial lipochitooligosaccharide signal (the Nod factor), whose synthesis is specified by the bacterial nod genes (Dénarié et al. 1992). The Nod factors are perceived and transduced by a specific plant signal transduction pathway (Limpens and Bisseling 2003; Oldroyd and Downie 2004). Some of the plant genes involved (synonymously called the "common SYM" or the "does not make infection" [DMI] genes) also are required for establishment of the symbiosis with arbuscular mycorrhizal fungi (the AM symbiosis). In Medicago truncatula, three DMI genes have been described: DMII, DMI2, and DMI3 (Catoira et al. 2000; Wais et al. 2000). The DMI2 gene and its orthologs (NORK of M. sativa and SYMRK of Lotus japonicus) have been shown to encode receptorlike kinases (RLKs) with large extracellular regions containing three leucine-rich repeats (Endre et al. 2002; Stracke et al. 2002). Because dmi mutants are able to respond to Nod factors in terms of a rapid calcium flux and root hair deformation (Catoira et al. 2000; Shaw and Long 2003), it appears that Nod factor perception occurs upstream of the DMI2 receptor. Recently, genes required for these early responses have been identified (NFP of $M$. truncatula, SYM10 of Pisum sativum, NFR1, and NFR5 of L. japonicus) and shown to encode lysinelike motif (LysM)-RLKs, which are likely to be Nod factor-binding receptors (Ben Amor et al. 2003; Limpens et al. 2003; Madsen et al. 2003; Radutoiu et al. 2003; Walker et al. 2000). Activation of the LysM-RLKs is postulated to activate the DMI2 receptor and the common 
SYM pathway. However, the NFP and SYM10 genes are not required for establishment of the AM symbiosis; therefore, it appears that mycorrhizal fungi must use a different mechanism to activate DMI2.

From this genetic analysis, it is clear that the DMI2 receptor plays a key and pivotal role in establishing root endosymbiosis with two different symbionts - a bacterium and a fungus. In the rhizobial symbiosis, DMI2 is required for Nod factor responses in the epidermal cells (calcium spiking and induction of MtENOD11) (Catoira et al. 2000; Vernoud et al. 2000; Wais et al. 2000). It also is required for elicitation of cell division in cortical cells and for Nod factor-induced ENOD40 expression in the pericycle and cortex (Catoira et al. 2000). However, it is not known whether these responses in the internal tissues are cell autonomous events or depend on signals elicited by DMI2dependent signal transduction in the epidermal cells. To date, the only work on the expression of $D M I 2$ or its potential orthologs is the report that the SYMRK gene is expressed constitutively in roots and is not induced by Nod factors or rhizobia (Stracke et al. 2002). In this article, we have studied the expression of the M. truncatula DMI2 gene with the aim of analyzing the regulation of its expression and revealing potential roles during nodulation. This work has used fusions of the promoter region of DMI2 with the $\beta$-glucuronidase (GUS) marker gene, a strategy which allows a sensitive mechanism for detecting the expression pattern of weakly expressed genes and which has faithfully reproduced the expression pattern of several nodulin genes in M. truncatula (de Billy et al. 1991; Fang and Hirsch 1998; Journet et al. 2001; Pichon et al. 1992; Vernoud et al. 1999).

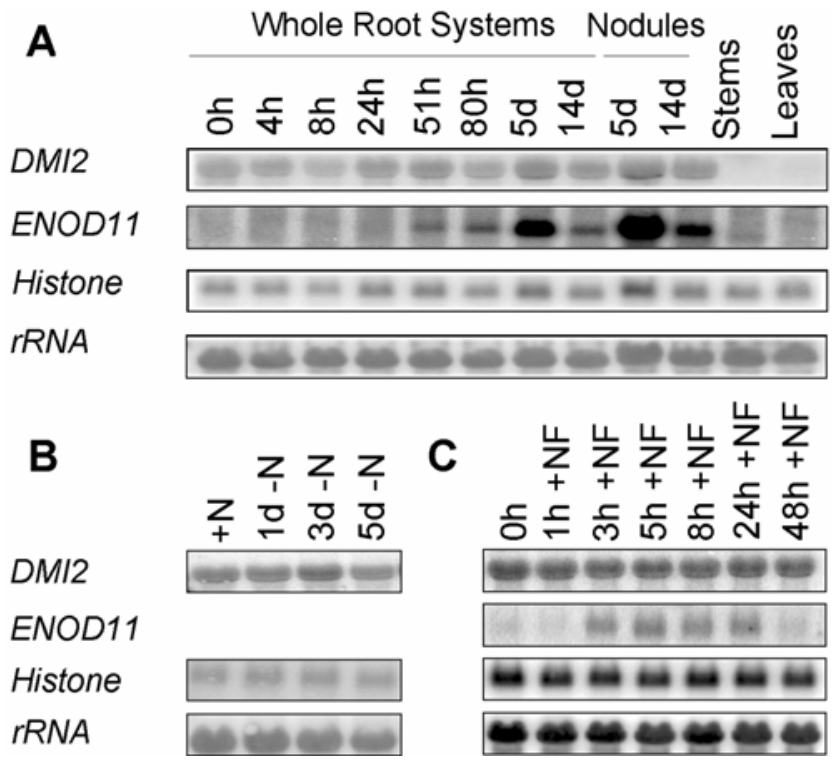

Fig. 1. Regulation of expression of the $D M I 2$ gene. The abundance of DMI2 mRNA was determined by Northern analysis in experiments on aeroponically grown plants. A, Expression during nodulation and in different organs of the plant. Whole root systems or isolated nodules were harvested at different times ( $\mathrm{h}=$ hours, $\mathrm{d}=$ days) after inoculation with Sinorhizobium meliloti 2011; leaves and stems were isolated at $0 \mathrm{~h}$. B, Expression in roots during nitrogen starvation. Plants grown on a nitrogen source of $5 \mathrm{mM}$ ammonium nitrate $(+\mathrm{N})$ were starved of nitrogen, and whole root systems were analyzed at different times $(\mathrm{d}-\mathrm{N})$. C, Expression in roots following addition of Nod factors. Roots of 5-day-old plants without a nitrogen source $(0 \mathrm{~h})$ were treated with $10^{-8} \mathrm{M}$ Nod factors and whole roots systems were analyzed at different times $(\mathrm{h}+\mathrm{NF})$. The abundance of mRNA for MtENOD11 and Histone genes were used as controls. The RNA loading was verified by hybridization with an rRNA probe.

\section{RESULTS}

Analysis of DMI2 expression

during nodulation and in different organs.

In order to determine whether the overall level of expression of the DMI2 gene is regulated during nodulation, the level of DMI2 mRNA was analyzed by Northern hybridization during a nodulation experiment. Plants were grown in aeroponic containers, starved of nitrogen for 4 days, and inoculated with Sinorhizobium meliloti. Whole root systems were harvested from $4 \mathrm{~h}$ to 14 days after inoculation and nodules were isolated at 5 and 14 days. The data on DMI2 mRNA levels (Fig. 1A) were quantified and adjusted to equal gel loadings (using the rRNA signals) and compared with changes in expression of the early nodulin gene MtENOD11 (an induced gene) and histone (a housekeeping gene). As reported in previous studies (Journet et al. 2001), $M t E N O D 11$ was strongly induced during nodulation, with an increase in its mRNA being detectable by $51 \mathrm{~h}$, and the level of its mRNA being much higher in young nodules than in roots (Fig. 1A). DMI2 showed no such strong induction and the level of its mRNA varied by less than $30 \%$ throughout the experiment, except at 5 days, when an increase of approximately $70 \%$ was seen in both the root systems and isolated nodules. Histone showed similar changes to DMI2 (less than $15 \%$ variation between the changes in expression of the two genes), except that it was much more highly expressed. In contrast to the underground organs, DMI2 mRNA was much less abundant (approximately $8 \%$ of the level) in the stems and leaves of the plants. Examination of the $M$. truncatula expressed-sequence tag (EST) banks (Journet et al. 2002; Quackenbush et al. 2001) revealed 18 clones of the DMI2 gene, 12 of them identified in root and nodule cDNA libraries and 5 in mixed tissue libraries; only 1 clearly came from a bank of aerial organs (clone GenBank BF640745 from the $M$. truncatula "local and systemic leaves following insect herbivory" library) (Quackenbush et al. 2001).

We also investigated whether the DMI2 gene is induced by nitrogen starvation or addition of Nod factors. The level of mRNA of this gene in roots was similar (less than $30 \%$ variation) (Fig. 1B) whether the plants were grown on ammonium nitrate or starved of nitrogen for up to 5 days before inoculation. Moreover, a similar basal level of DMI2 mRNA (less than $12 \%$ variation) was observed in roots following addition of Nod factors, whereas MtENOD11 clearly was transiently induced by this treatment (Fig. 1C).

\section{Cellular localization of DMI2 expression in roots and nodules.}

To analyze the cell-specific expression of the DMI2 gene in roots and nodules, constructs were made of the promoter and upstream regions of the gene fused to the GUS marker gene. Two fusions were made: p1.2DMI2-GUS and p3.0DMI2-GUS, corresponding to $D M I 2$ promoter and upstream regions of 1.2 and $3.0 \mathrm{kbp}$, respectively. These regions are functional because they direct complementation of $d m i 2$ mutants by the DMI2 gene (Endre et al. 2002). These fusions were introduced into Agrobacterium rhizogenes and the strains were used to produce composite plants in which the roots, but not the shoots, are transgenic (Boisson-Dernier et al. 2001). Therefore, each plant results from a different transformation event and analysis of many plants eliminates the possibility that the observed GUS expression is due to the position of insertion of the transgene. In this article, at least 20 GUS-expressing plants were observed for each treatment or time point. The transgenic roots and nodules were analyzed histologically for GUS activity. Unless otherwise stated, results are described using the p3.ODMI2GUS fusion and the S. meliloti 2011(pXLGD4) strain (Ardourel et al. 1994) which carries a constitutive hemA-lacZ fusion. 
In noninoculated plants, GUS activity was observed over most of the root systems; however, noticeably, no activity was detected in the root apices (Fig. 2A and B). It was not possible to define where expression started in the roots, because the GUS activity was very low in the developing root hair zone (relative, for example, to expression from the MtENOD11 or 12 promoters) (Journet et al. 2001; Pichon et al. 1992). However, GUS activity increased progressively in this zone and was highest in the region where the root hairs had just attained their maximal length (Fig. 2B). The older regions of the roots and, particularly, the primary roots showed lower GUS activity than the lateral roots (Fig. 2A). On root sections, most of the positive transgenic lines showed GUS staining in the cortex and also in the epidermis, including the root hairs (Fig. 2C).

In order to examine expression from the $p D M I 2$ promoter during nodulation, the transgenic composite plants were transferred to growth pouches. After 1 week, part of the root system was excised and analyzed histochemically for GUS activity. Sets of plants then either were inoculated with $S$. meliloti or $10^{-8} \mathrm{M}$ Nod factors or mock inoculated, and GUS expression was analyzed in the remaining root system 2,3 , or 5 days later. At 2 days following rhizobial inoculation, $71 \%$ of the plants showed a clear increase in expression in the susceptible zone, which was significantly different than the number of plants reacting to the mock inoculation (Table 1). This rhizobial-induced expression generally was confined to the secondary roots and was not uniform but appeared as semidiscrete patches in the cortex (Fig. 2D). At 3 days, the increased cortical expression clearly was associated with the developing nodule primordia, whereas lateral root primordia showed basal or lower expression (Fig. 2E). At this time point, the number of plants responding to rhizobial inoculation was again significantly different than the mock inoculation, whereas addition of Nod factors did not lead to a significant change compared with this control (Table 1). At 5 days, $83 \%$ of the plants showed developing nodules emerging from the root, which showed stronger GUS expression than at the initial time point (Fig. 2F). At all three time points, the surrounding tissues of the root and the nonreactive roots showed activity similar to that of the roots harvested before inoculation (Table 1). Moreover, inoculation did not inhibit expression in the newly developing root tips and lateral roots that developed subsequent to rhizobial and Nod factor inoculation; these regions of the root expressed the DMI2 gene at the basal level (Fig. 2F).

In order to pinpoint the localization of induced DMI2 expression in relation to the developing infections, the bacteria in over 30 pDMI2-GUS plants were counterstained using Magenta-gal, due to their expression of the constitutive hemAlacZ fusion. In addition, over 30 plants were assayed for GUS expression using Magenta-gluc and the bacteria were stained with X-gal (5-bromo-4-chloro-3-indolyl- $\beta$-D-galactoside). Examination of these plants revealed that the youngest primordia that expressed the GUS fusion had not yet been infected (Fig. $2 \mathrm{G})$, while slightly older primordia, with a limited ramification of the infection threads, showed similar, increased GUS expression in both infected and uninfected cells (Fig. 2H). Increased GUS activity was not observed specifically in cells in the epidermis or outer cortex through which the infection threads were passing.

Sectioning of some of the primordia and young, spherical nodules (assayed to measure the relative GUS activity in the different tissues) showed that the increased expression occurred throughout the internal tissues of the developing nodule, from the root stele towards the emerged apex, whereas the peripheral nodule tissues and the surrounding root tissues showed relatively little activity (Fig. 2I). At this stage, the internal tissues did not show differentiation into zones. Expression of pDMI2-GUS also was observed in sections of older nodules, 7 to 10 days following inoculation, in which the typical zonation of indeterminate nodules was apparent: a distal, apical, and persistent meristem (zone I) followed by zones of increasing cell age, comprising an infection zone (zone II), an interzone (II-III), and a nitrogen-fixation zone (zone III) (Vasse et al. 1990). Expression in all GUS-positive plants was localized in a small region at the distal part of the nodule (Fig. 2J). A similar localization of expression also was seen with the p1.2DMI2GUS fusion, although GUS activity from the shorter promoter generally was lower (data not shown). This result suggests that the $c i s$-acting elements required for the cell-specific expression must occur in the 1.2-kbp fragment. In addition the two widely used S. meliloti strains, 2011 or 1021 (Wais et al. 2002) induced similar patterns of expression (data not shown). Staining with 4',6-diamidino-2-phenylindole (DAPI) to reveal the nuclei (Fig. 2M) showed that the pDMI2-GUS expression in the apical zone of the nodule (Fig. $2 \mathrm{~K}$ ) occurred in cells proximal to the meristem. Using Nomarski microscopy to observe the infection threads (Fig. 2L), it appears that the strongest GUS activity occurred in cells distal to the main infection zone. Therefore, GUS activity, expressed from the $p D M I 2$ promoter, was located mainly in a region between the meristem and the main part of the infection zone. The transgenic plants showing highest GUS activity revealed expression in other regions of the nodule that were not detectable with low GUS-expressing lines. Many of these high-expressing lines showed GUS activity in the central, nitrogen-fixing tissue, and 2 of 22 plants expressed GUS activity also in or around the vasculature of both the nodule and the associated root irrigating the nodule (data not shown). In all of the GUS-positive plants, the nodule cortex showed either no or very low GUS expression. It should be

Table 1. Changes in expression of DMI2 following treatment of roots with either Sinorhizobium meliloti or Nod factors ${ }^{y}$

\begin{tabular}{|c|c|c|c|c|c|c|c|c|}
\hline \multirow[b]{3}{*}{ Treatment } & \multirow[b]{3}{*}{ Time point (days) } & \multirow[b]{3}{*}{ No. of plants tested } & \multicolumn{6}{|c|}{ No. of plants responding ${ }^{\mathrm{z}}$} \\
\hline & & & \multicolumn{3}{|c|}{ Susceptible zones } & \multicolumn{3}{|c|}{ Surrounding tissues } \\
\hline & & & - & $\mathbf{0}$ & + & - & $\mathbf{0}$ & + \\
\hline$\overline{\text { Mock }}$ & 3 & 32 & 0 & 25 & 7 & 1 & 31 & 0 \\
\hline \multirow{3}{*}{ S. meliloti } & 2 & 21 & 0 & 6 & $15 \mathrm{a}$ & 0 & 21 & $0 \mathrm{c}$ \\
\hline & 3 & 37 & 0 & 14 & $23 \mathrm{a}$ & 1 & 32 & $4 \mathrm{c}$ \\
\hline & 5 & 31 & 0 & 5 & $26 \mathrm{a}$ & 3 & 28 & $0 \mathrm{c}$ \\
\hline Nod factors & 3 & 25 & 0 & 20 & $5 \mathrm{~b}$ & 2 & 22 & $1 \mathrm{c}$ \\
\hline
\end{tabular}

${ }^{\mathrm{y}}$ Part of the root system of transgenic plants expressing the $p 3.0 D M I 2-G U S$ construct was assayed histochemically for $\beta$-glucuronidase (GUS) activity and then the rest of the root system was treated either by a mock inoculation, with $S$. meliloti, or with $10^{-8} \mathrm{M}$ Nod factors for 2 , 3 , or 5 days before re-assaying GUS expression. The GUS activity in the susceptible zones of the secondary roots in which nodules appear or in the surrounding tissues was compared with the initial time point for each plant and scored as either a decrease $(-)$, no change $(0)$, or increase $(+)$ in expression.

${ }^{\mathrm{z}} \mathrm{a}=$ Data significantly different than mock inoculation $(P<0.002), \mathrm{b}=$ data not significantly different than mock inoculation $(P=0.86)$, and $\mathrm{c}=$ data not significantly different than mock inoculation $(P>0.15)$. 

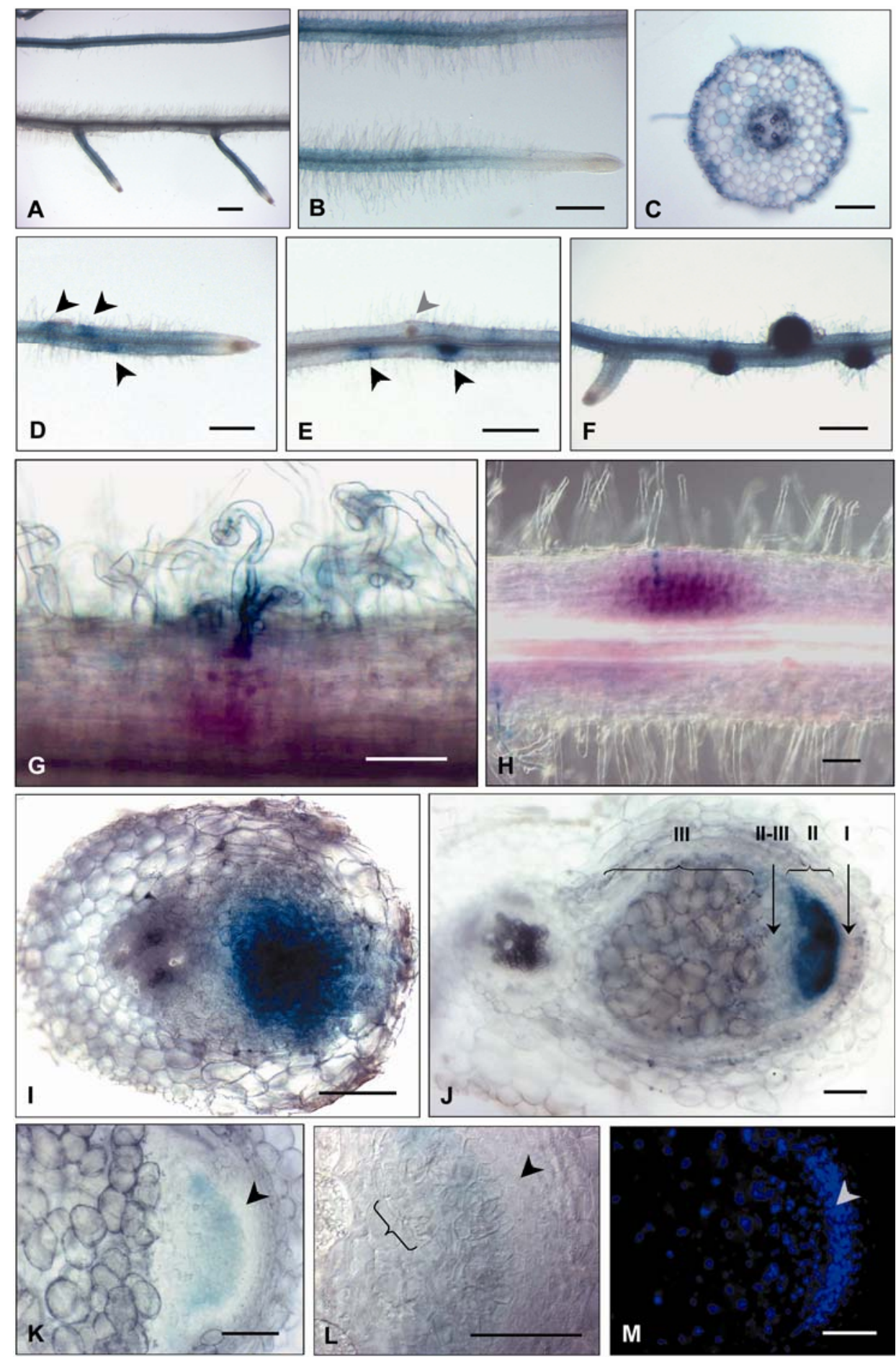

Fig. 2. Histochemical localization of $p D M I 2-G U S$ expression throughout various stages of nodulation in Medicago truncatula. $\beta$-Glucuronidase (GUS) activity was localized in transgenic plants expressing the p3.0DMI2-GUS fusion. A through $\mathbf{C}$, Roots of nitrogen starved plants. A, Whole root segments of primary and secondary roots, showing GUS expression. B, Secondary roots showing lack of GUS expression in the root apices and increasing expression in the developing root hair zone. C, Section, $100 \mu \mathrm{m}$ thick, of a secondary root cut in the region behind the root apex, showing pDMI2-GUS expression in the root hairs and epidermal and cortical cells. D through $\mathbf{F}$, Whole root segments of secondary roots showing expression of $p D M I 2-G U S$ in the developing nodule primordia (black arrows) at $\mathbf{D}, 2, \mathbf{E}, 3$, and $\mathbf{F}, 5$ days after inoculation. The gray arrow shows a lateral-root primordium, with very low $p D M I 2-G U S$ expression. $\mathbf{G}$ through $\mathbf{H}$, Whole root segments at $\mathbf{G}, 2$ and $\mathbf{H}, 3$ days after inoculation showing $p D M I 2-G U S$ expression in magenta and LacZ expression from the rhizobia in blue. Expression of $p D M I 2-G U S$ occurs before infection of the primordium cells and is not correlated with infection threads in the cells. I, Section of developing nodule at 5 days after inoculation showing pDMI2-GUS expression in the central, undifferentiated tissues of the developing nodule. $\mathbf{J}$, Longitudinal section of 10-day-old nodule showing strong GUS expression in the pre-infection zone. The anatomical nodule zones are marked. $\mathbf{K}$ through $\mathbf{M}$, Identical nodule section observed by $\mathbf{K}$, light microscopy to show GUS activity, L, Nomarski microscopy to show infection threads, and $\mathbf{M}$, dark field after diamidino-2-phenylindole (DAPI) staining to show the nuclei. The arrows are identically placed, in the meristematic region of these three images. Bars $=100 \mu \mathrm{m}$, except in $\mathbf{A}, \mathbf{B}$, and $\mathbf{D}$ through $\mathbf{F}$, where bars $=500 \mu \mathrm{m}$. 
noted that the intensity of the GUS staining in the preinfection zone of the nodule was always very much stronger than that associated with the nitrogen-fixing zone or the vasculature.

\section{DMI2 mRNA levels in different mutant genotypes.}

To investigate whether $D M I 2$ expression is regulated by known symbiotic genes, the DMI2 mRNA levels were analyzed in roots of various symbiotic mutants ( $f f p, d m i l, d m i 3, n s p l$, $n s p 2$, and $h c l$ ) and also in different allelic mutants of dmi2 (TR25, TR26, P1, and R38). Genetic analysis has shown that NFP acts upstream; DMII acts at the same level; and DMI3, NSP1, NSP2, and HCL all appear to act downstream of $D M I 1 / D M I 2$ in the Nod factor signal transduction pathway (Catoira et al. 2000, 2001; Ben Amor et al. 2003; Oldroyd and Long 2003). DMI1, DMI2, and DMI3, but not the other four genes, also are required for the establishment of the AM symbiosis. The level of DMI2 mRNA measured in roots of the wild-type and most of the symbiotic mutants (Fig. 3) varied by less than $29 \%$. However, two of the dmi2 mutants, TR25 and TR26, contained much lower levels of DMI2 mRNA (less than $18 \%$ of the wild type) compared with mutants P1 and R38. The size of the DMI2 mRNA was similar in all plant lines tested.

\section{DISCUSSION}

The DMI2 gene of M. truncatula was identified in screens for $\mathrm{Nod}^{-}$mutants; thus, all alleles reported to date are either completely or severely restricted in nodulation. Further analysis has revealed that $d m i 2$ mutants are blocked in infection at the root epidermis and that these cells are defective in most Nod factor responses, including induction of some early nodulin genes and calcium spiking (Catoira et al. 2000; Wais et al. 2000). Thus, the gene plays an essential role in the early steps of Nod factor signal transduction leading to infection of the epidermal cells of the root. By studying the expression of the DMI2 gene and fusions of the DMI2 promoter with the GUS gene marker, data presented in this article suggest that DMI2 plays also a role in the root cortex during early nodule development and in the preinfection zone of nodules.

\section{Localization of DMI 2 expression.}

Studies reported here using GUS fusions have shown that the $D M I 2$ gene is expressed in a very specific region of the nodules, located between the meristem and the main part of the infection zone (Fig. 2J through $\mathrm{M}$ ). A similar, narrow zone of DMI2 mRNA abundance recently has been shown by in situ hybridization (Mirabella 2004), thus validating the GUS fusion approach. This zone of expression has been termed the "prein-

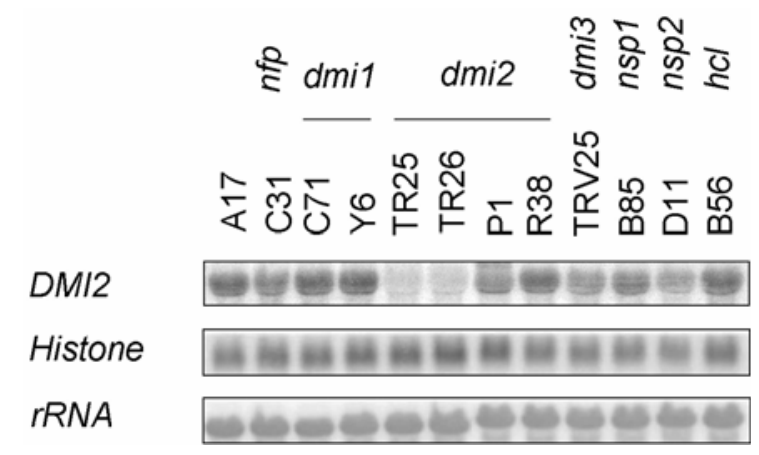

Fig. 3. Expression of the DMI2 gene in roots of different symbiotic mutants. Aeroponically grown plants of the indicated symbiotic mutants (gene and mutant) were starved of nitrogen for 4 days and RNA levels were analyzed by Northern analysis of whole root systems. A17 is the wild-type line. fection zone" (Pichon et al. 1992) and is characterized by the induction of several nodulin genes of $M$. truncatula, including MtENOD12 (Pichon et al. 1992), MtENOD11 (Journet et al. 2001), MtN1 (Gamas et al. 1998), MtN6 (Mathis et al. 1999), and MtAnnl (de Carvalho-Niebel et al. 1998). By comparison of the depths of the zones in which the nodulin genes are expressed, DMI2 and MtENOD11 appear to have very similar, narrow expression patterns in this apical region of the nodule. Indeterminate nodules show a gradation of cells of increasing age from the meristem to the base (Vasse et al. 1990); therefore, this localization of expression suggests that the DMI2 gene is expressed transitorily during growth and differentiation of the nodule. However, it is noteworthy that DMI2 also appears to be expressed, albeit at a lower level, in the nitrogen-fixing zone of the nodule.

In roots, studies with GUS fusions have shown that DMI2 is expressed in the epidermis and cortex and throughout most of the root system but not in the root apices (Fig. 2A and B). Highest expression was observed in the younger part of lateral roots. During nodulation, the gene is strongly induced in the nodule primordia, forming particularly on the lateral roots, relative to the low expression in the surrounding tissues and newly developing roots. The low number of cells that showed induction did not lead to an obvious increase in the level of mRNA at early time points in the root systems as measured by Northern analysis (Fig. 1A), thus emphasizing the importance of studying spatial changes in gene expression in addition to overall mRNA levels. At 2 days following rhizobial inoculation, induction of DMI2 could be seen clearly in patches of cells in the cortex and, at 3 to 5 days, this induction clearly was confined to the nodule primordia and the central, undifferentiated tissues of the young emerging nodules (Fig. 2D through F). At these stages of nodulation, the expression of DMI2 resembles more closely the expression pattern of MtENOD20 (Vernoud et al. 1999) and MsENOD40-1 and -2 (Fang and Hirsch 1998), rather than MtENOD11 and MtENOD12, which are not induced in the primordia. However, the ENOD genes also are induced in the epidermal and cortical cells through which infection threads are initiated or passing (Journet et al. 2001; Pichon et al. 1992; Vernoud et al. 1999). We did not find a correlation between increased $p D M I 2-G U S$ expression and the presence of infection threads, as shown also in nodules. Despite certain similarities with the expression patterns of some nodulin genes, it is noteworthy that the expression of DMI2 differs considerably from these genes by its basal level of expression in roots and lack of overall increase in mRNA levels in nodules (Fig. 1A).

\section{Does the expression pattern of DMI2 limit symbiotic responses?}

Studies of nodulation in $M$. sativa have shown that the symbiosis with rhizobia is initiated in a susceptible zone behind the root apices primarily of lateral roots (Bhuvaneswari et al. 1981; Caetano-Anollés and Gresshoff 1991). Moreover, the expression of MtENOD11 and MtENOD12 by rhizobia also is initiated in a similar zone (Journet et al. 2001; Pichon et al. 1992). Although the low level of expression of the pDMI2$G U S$ fusion in roots has precluded a precise localization of the start of DMI2 expression in roots, it is clear that the gene is poorly expressed in the apices and is more strongly expressed in the susceptible zone. Because both nodulation and expression of the two early nodulin genes depend on DMI2 in roots, it appears that the pattern of expression of the DMI2 gene may be a factor localizing the initiation of symbiotic activities to the start of the susceptible zone. However, the presence of similar levels of DMI2 mRNA in roots of plants grown on high levels of an inorganic nitrogen source and following nitrogen starvation (Fig. 1B) suggests that the level of expression of 
DMI2 is not a factor, restricting establishment of the LR symbiosis to conditions of nitrogen deprivation.

In nodules, it is tempting to speculate that the expression of the DMI2 receptor limits the pattern of induction of some early nodulin genes to the preinfection zone of the nodule. However, it should be noted that some of these nodulin genes have complex patterns of regulation (e.g., MtENOD11 is induced by a DMI-independent pathway in the root cortex by a diffusible AM fungal factor) (Kosuta et al. 2003) and it has not been shown that their expression in nodules requires DMI2. Moreover, the lack of correlation of expression of DMI2 with nodulin genes during early stages of infection suggests that other factors (e.g., receptor activation, other genes, and proteins) also may regulate or limit expression of the ENOD genes. Clearly, in this regard, the expression patterns of other genes required for Nod factor responses, such as the symbiotic LysM-RLKs, DMII, and DMI3, also should be investigated in order to verify whether the regulation of DMI2 expression may be a factor limiting symbiotic responses.

\section{Regulation of $D M I 2$ expression.}

As shown for SYMRK of L. japonicus (Stracke et al. 2002), we did not find an induction of the DMI2 gene in roots by Nod factors (Table 1; Fig. 1C) or by nitrogen starvation (Fig. 1B). However, DMI2 is strongly induced in nodule primordia before infection (Fig. 2) and the formation of these primordia requires a signal transduction pathway that is dependent on the symbiotic genes NFP, DMI1, DMI2, DMI3, NSP1, and NSP2 (Ben Amor et al. 2003; Catoira et al. 2000; Oldroyd and Long 2003). Thus, by extrapolation, the expression of $D M I 2$ in the primordia should require its own and other genes defining this Nod factor signal transduction pathway, although this may not be a cellautonomous event. We investigated whether these genes also are required for expression of DMI2 in uninoculated roots. The same level of expression of the DMI2 gene was observed in roots of all these mutants (except dmi2), suggesting that the basal level of DMI2 expression in roots does not require the function of these other genes. In contrast, roots of some of the $d m i 2$ mutants had very low levels of mRNA from the mutated gene, whereas other alleles accumulated dmi2 mRNA to wildtype levels (Fig. 3). Reduced levels of dmi2 mRNA in TR25 (dmi2-1) recently have been reported by Mitra and associates (2004) and these authors have suggested that it may be due to an RNA surveillance mechanism called nonsense-mediated decay that detects and destroys mRNAs that contain a premature termination codon (Wagner and Lykke-Andersen 2002). The low levels of DMI2 mRNA in TR25 and TR26 (which contain mutations leading to premature termination codons) and higher levels in the P1 and R38 alleles (which contain point mutations leading to a loss of exon6 and to a missense mutation, respectively) (Endre et al. 2002) are consistent with this hypothesis. However, these latter alleles are leaky for symbiotic phenotypes (Endre et al. 2002; Wais et al. 2000); therefore, we cannot eliminate the possibility that a functional DMI2 receptor positively regulates its own expression in roots.

\section{Role of DMI2.}

Because $d m i 2$ mutants develop normally when grown with a combined nitrogen source, it appears that DMI2 is essential only for establishing root endosymbioses. The much higher levels of mRNA in roots and nodules compared with leaves and stems (Fig. 1 and EST data) suggest a role in nodules in addition to roots and do not exclude functions in the aerial organs. Recently, roots of $d m i 2$ mutants have been found to be more sensitive to touch than those of wild-type plants (Esseling et al. 2004), suggesting that the gene may have a subtle, nonsymbiotic role which should be investigated further.
Because dmi2 mutants are blocked in infection of the epidermal cells by both rhizobia and AM fungi, a common symbiotic role of the gene has been suggested in the very early steps of infection. In the LR symbiosis, DMI2 clearly plays a role in Nod factor-mediated signal transduction in roots prior to infection and, moreover, also is involved in establishing the nodule primordia (Catoira et al. 2000). The expression of DMI2 in epidermal and cortical cells before inoculation is consistent with a role in perceiving the symbionts before allowing infection to proceed. In accord with an infection role in roots, the simplest explanation for the induction of the DMI2 gene in the nodule primordium and in the preinfection zone of the nodule is that the DMI2 receptor is required to prepare for infection during nodule organogenesis. Bacterial nod genes required for Nod factor synthesis seem to be induced not only in a molecular dialogue before root infection but also in the apical zone of nodules (Schlaman et al. 1998); therefore, it appears that DMI2 is mediating Nod factor signal transduction in both roots and nodules. Moreover, the DMI2 gene appears to be expressed, albeit at a lower level, in the fixation zone of the nodule, thus suggesting that DMI2 may play a role in continual interactions between the plant and its functioning bacterial symbiont. From the expression pattern of the gene in proximity to infecting or nitrogen-fixing rhizobia, we cannot state whether the signal that binds to and activates the DMI2 receptor is more likely to be derived from the bacterium or the plant (or, for the AM symbiosis, from the fungus); at present, the ligands for DMI2 and related proteins remain unknown.

In conclusion, our studies on the localization of DMI2 expression suggest that the gene plays a specific role in the root cortex and in nodules preceding or leading to rhizobial infection. In concurrence with its role in root epidermal cells, these results support the idea that Nod factor perception and transduction leading to rhizobial infection occur continuously during development of indeterminate nodules.

\section{MATERIALS AND METHODS}

\section{Growth conditions.}

M. truncatula Gaernt. cv. Jemalong lines A17 or J5 (Thoquet et al. 2002) and the mutant lines $n f p$ C31 (Ben Amor et al. 2003); dmil C71 and Y6 (Catoira et al. 2001); dmi2 TR25, TR26, P1, and R38 (Catoira et al. 2000; Endre et al. 2002); dmi3 TRV25; nspl (Catoira et al. 2000); nsp2 (Oldroyd and Long 2003); and hcl (Catoira et al. 2001) were grown in aeroponic chambers in a 16 -h photoperiod at $23^{\circ} \mathrm{C}$, usually for 2 to 3 weeks on a medium containing $5 \mathrm{mM} \mathrm{NH}_{4} \mathrm{NO}_{3}$ as described by Navarro-Gochicoa and associates (2003b). Plants then were starved of nitrogen for 4 days, unless otherwise stated, by replacing the culture medium with the same one lacking a nitrogen source. In some experiments, S. meliloti 2011 (pXLGD4) (Ardourel et al. 1990) then was added to the root medium. Whole root systems or organs were harvested at different times (as indicated in the figure legends), frozen in liquid nitrogen, and stored at $-80^{\circ} \mathrm{C}$ before total RNA extraction. For the experiment in Figure 1C, seedlings were grown for 5 days in aeroponic chambers without a nitrogen source before treatment with $10^{-8} \mathrm{M}$ Nod factors (biologically produced factors containing predominantly NodSmIV[Ac, S, C16:2], prepared essentially as described by Roche and associates [1991]).

\section{Construction of $\mathrm{MtDMI} 2$ promoter GUS fusions.}

The p3.ODMI2-GUS construct was prepared by amplifying the $5^{\prime}$ region of the DMI2 gene from the BAC clone MtHI67A11 (Endre et al. 2002) using the primers (TATAAGCTTAT 
GATAAATAGTTTCTTAAA) and (ATAGGATCCAATCTGA AAGAGATTTTACCC) and cloning via the HindIII and BamHI sites in the promoter probe vector, pPR97 (Szabados et al. 1995). For the p1.2DMI2-GUS construct, the 5 ' regions of $D M I 2$ were amplified by polymerase chain reaction (PCR) from plasmid BRC1667 (Endre et al. 2002) using the primers (M13 reverse) and (CATAATCTAGAAGAGATTTTAC), followed by cloning via the $K p n I-X b a \mathrm{I}$ sites in front of GUS in the binary vector pGreenII 0029 (Hellens et al. 2000). Therefore, the constructs contained 3,077 and 1,243 bp of promoter region finishing 1 and 8 bp upstream of the initiating ATG in the p3.ODMI2-GUS and the p1.2DMI2-GUS constructs, respectively. The constructs were verified by DNA sequencing and the plasmids then were transformed into A. rhizogenes ArQual by electroporation.

\section{M. truncatula transformation and treatment of transgenic plants.}

Composite plants expressing the $p D M I 2-G U S$ fusions in their roots were produced using the above $A$. rhizogenes strains as described by Boisson-Dernier and associates (2001). Plants producing roots on kanamycin at $20 \mu \mathrm{g} / \mathrm{ml}$ were transferred into growth pouches, two to three plants per pouch, and nontransformed roots were removed. The plants were grown for approximately 11 days with a medium containing $0.25 \mathrm{mM}$ $\mathrm{NH}_{4} \mathrm{NO}_{3}$. Part of the root system containing several secondary roots then was excised and assayed histochemically for GUS activity. The next day, the rest of the root system was treated by pipetting aqueous solution at $1 \mathrm{ml} / \mathrm{plant}$ over the root systems containing either $10^{8}$ bacteria, $10^{-8} \mathrm{M}$ NodSm factors, or just water (mock inoculation). Part of the root system was harvested at various times after inoculation (2, 3, or 5 days) and assayed for GUS activity as before. At least 20 plants were used for each time point. For the quantitative analysis in Table 1, roots were scored blind for a decrease, no change, or increase in GUS activity compared with the initial time point, either in the zone of the secondary roots, just behind the tips where nodules are predicted to develop (the susceptible zone), or in the surrounding regions. The data were analyzed by the $\chi^{2}$ test of equality of multinomial distribution using the prop. test of the Splus software (version 3.4, release 1 for Sun SPARC; Mathsoft Inc., Cambridge MA).

\section{Histochemical localization of GUS activity.}

Histochemical fixation and measurement of GUS activity of whole roots and nodules were performed as described by Vernoud and associates (1999), generally using X-gluc as substrate although, in some experiments, Magenta-gluc was used. Stained whole roots were fixed with $2.5 \%$ paraformaldehyde and embedded into 3\% agarose before making 150 $\mu$ m-thick sections using a BioRad Micro Cut H1200 vibratome. Nodules (from 7 p1.2DMI2-GUS and 22 p3.ODMI2GUS plants) were prefixed with $0.5 \%$ paraformaldehyde, embedded in $2 \%$ agarose, and sliced into $100-\mu \mathrm{m}$-thick sections before staining. Generally, both roots and nodules were stained for GUS activity for between 16 and $24 \mathrm{~h}$, because the activity was low. Double detection of pDMI2-GUS expression and the LacZ activity of the bacteria was carried out as described by Pichon and associates (1994). Sections were observed by bright-field microscopy for roots and nodules. Nodule sections also were observed with Nomarski microscopy to view infection threads and with epifluorescent microscopy following DAPI $(0.5 \mu \mathrm{g} / \mathrm{ml})$ coloration to view nuclei. The roots were observed by phase contrast microscopy (Fig. 2H). Digital pictures were taken with a Leica camera using the Leica DC Viewer software and assembled using Adobe Photoshop (version 7.0).

\section{RNA isolation and Northern analysis.}

The methods to extract and quantify total RNA and prepare Northern blots are described by Navarro-Gochicoa and associates (2003a). DNA used to prepare the specific DMI2 probes was a PCR product amplified from cDNA corresponding to the highly specific extracellular domain of unknown function. Control probes were produced from DNA fragments of MtENOD11 (Journet et al. 2001), histone, and rRNA genes as described by Navarro-Gochicoa and associates (2003a). Hybridization was visualized using a Molecular Dynamics PhosphoImager and the signals were quantified using the ImageQuant 5.0 software. The signals of DMI2, ENOD11, and histone mRNA then were adjusted to identical loadings of rRNA.

\section{ACKNOWLEDGMENTS}

Work in the French laboratory was financed partly by the European Community Human Potential Program (Research Training Network HPRN-CT-2002-00251). A. Bersoult was financed by a Doctoral grant from the French Ministère de l'Education Nationale, de l'Enseignement Supérieur et de la Recherche. The Hungarian group acknowledges the financial support of the Ministry of Education (NKFP4/023/2001) and the Hungarian National Research Foundation (OTKA M045657). The two laboratories gratefully acknowledge financial support from the INRAHungary International Bilateral Collaboration Program. We would like to thank our colleagues F. de Billy and E. P. Journet for help and advice with the GUS localization; F. Maillet and J. Dénarié for supplying the Nod factors; B. Mangin (Biometrie) for the statistical analysis; F. de Billy, E. P. Journet, and C. Gough (of our laboratory); and G. Endre (BRC-HAS) for critically reading the manuscript.

\section{LITERATURE CITED}

Albrecht, C., Geurts, R., and Bisseling, T. 1999. Legume nodulation and mycorrhizae formation two extremes in host specificity meet. EMBO (Eur. Mol. Biol. Organ.) J. 18:281-288.

Ardourel, M., Demont, N., Debellé, F., Maillet, F., De Billy, F., Promé, J.C., Dénarié, F., and Truchet, G. 1994. Rhizobium meliloti lipooligosaccharide nodulation factors: Different structural requirements for bacterial entry into target root hair cells and induction of plant symbiotic responses. Plant Cell 6:1357-1374.

Ben Amor, B., Shaw, S. L., Oldroyd, G. E. D., Maillet, F., Penmetsa, R. V., Cook, D., Long, S. R., Dénarié, J., and Gough, C. 2003. The NFP locus of Medicago truncatula controls an early step of Nod factor signal transduction upstream of a rapid calcium flux and root hair deformation. Plant J. 34:495-506.

Bhuvaneswari, T. V., Bhagwat, A. A., and Bauer, W. D. 1981. Transient susceptibility of root cells in four common legumes to nodulation by rhizobia. Plant Physiol. 68:1144-1149.

Boisson-Dernier, A., Chabaud, M., Garcia, F., Bécard, G., Rosenberg, C., and Barker, D. G. 2001. Agrobacterium rhizogenes-transformed roots of Medicago truncatula for the study of nitrogen-fixing and endomycorrhizal symbiotic associations. Mol. Plant-Microbe Interact. 14:695700.

Caetano-Anollés, G., and Gresshoff, P. M. 1991. Plant genetic control of nodulation. Annu. Rev. Microbiol. 45:345-382.

Catoira, R., Galera, C., de Billy, F., Penmetsa, R. V., Journet, E. P., Maillet, F., Rosenberg, C., Cook, D., Gough, C., and Dénarié, J. 2000. Four genes of Medicago truncatula controlling components of a Nod factor transduction pathway. Plant Cell 12:1647-1665.

Catoira, R., Timmers, A. C. J., Maillet, F., Galera, C., Penmetsa, R. V., Cook, D., Dénarié, J., and Gough, C. 2001. The HCL gene of Medicago truncatula controls Rhizobium-induced root hair curling. Development 128:1507-1518.

de Billy, F., Barker, D. G., Gallusci, P., and Truchet, G. 1991. Leghemoglobin gene transcription is triggered in a single cell layer in the indeterminate nitrogen-fixing nodule of alfalfa. Plant J. 1:27-35.

de Carvalho-Niebel, F., Lescure, N., Cullimore, J. V., and Gamas, P. 1998. The Medicago truncatula MtAnnl gene encoding an annexin is induced by Nod factors and during the symbiotic interaction with Rhizobium meliloti. Mol. Plant-Microbe Interact. 11:504-513.

Dénarié, J., Debellé, F., and Rosenberg, C. 1992. Signaling and host range variation in nodulation. Annu. Rev. Microbiol. 46:497-531.

Endre, G., Kereszt, A., Kevei, Z., Mihacea, S., Kalo, P., and Kiss, G. B. 2002. A receptor kinase gene regulating symbiotic nodule development. Nature 417:962-966. 
Esseling, J. J., Lhuissier, F. G. P., and Emons, A. M. C. 2004. A nonsymbiotic root hair tip growth phenotype in NORK-mutated legumes: Implications for nodulation factor-induced signaling and formation of a multifaceted root hair pocket for bacteria. Plant Cell 16:933-944.

Fang, Y., and Hirsch, A. M. 1998. Studying early nodulin gene ENOD40 expression and induction by nodulation factor and cytokinin in transgenic alfalfa. Plant Physiol. 116:53-68.

Gamas, P., de Billy, F., and Truchet, G. 1998. Symbiosis-specific expression of two Medicago truncatula nodulin genes, MtN1 and MtN13, encoding products homologous to plant defense proteins. Mol. PlantMicrobe Interact. 11:393-403.

Hellens, R. P., Edwards, E. A., Leyland, N. R., Bean, S., and Mullineaux, P. M. 2000. pGreen: A versatile and flexible binary Ti vector for Agrobacterium-mediated plant transformation. Plant Mol. Biol. 42:819-832.

Journet, E. P., El-Gachtouli, N., Vernoud, V., de Billy, F., Pichon, M., Dedieu, A., Arnould, C., Morandi, D., Barker, D. G., and GianinazziPearson, V. 2001. Medicago truncatula ENOD11: A novel RPRP-encoding early nodulin gene expressed during mycorrhization in arbuscule-containing cells. Mol. Plant-Microbe Interact. 14:737-748.

Journet, E. P., van Tuinen, D., Gouzy, J., Crespeau, H., Carreau, V., Farmer, M. J., Niebel, A., Schiex, T., Jaillon, O., Chatagnier, O. Godiard, L., Micheli, F., Kahn, D., Gianinazzi-Pearson, V., and Gamas, P. 2002. Exploring root symbiotic programs in the model legume Medicago truncatula using EST analysis. Nucleic Acids Res. 30:5579-5592.

Kistner, C., and Parniske, M. 2002. Evolution of signal transduction in intracellular symbiosis. Trends Plant Sci. 7:511-518.

Kosuta, S., Chabaud, M., Lougnon, G., Gough, C., Dénarié, J., Barker, D. G., and Bécard, G. 2003. A diffusible factor from arbuscular mycorrhizal fungi induces symbiosis-specific MtENOD11 expression in roots of Medicago truncatula. Plant Physiol. 131:952-962.

Limpens, E., and Bisseling T. 2003. Signaling in symbiosis. Curr. Opin. Plant Biol. 6:343-350.

Limpens, E., Franken, C., Smit, P., Willemse, J., Bisseling, T., and Geurts, R. 2003. LysM domain receptor kinases regulating rhizobial Nod factor-induced infection. Science 302:630-633.

Madsen, E. B., Madsen, L. H., Radutoiu, S., Olbryt, M., Rakwalska, M., Szczyglowski, K., Sato, S., Kaneko, T., Tabata, S., Sandal, N., and Stougaard, J. 2003. A receptor kinase gene of the LysM type is involved in legume perception of rhizobial signals. Nature 425:637-640.

Mathis, R., Grosjean, C., de Billy, F., Huguet, T., and Gamas, P. 1999. The early nodulin gene MtN6 is a novel marker for events preceding infection of Medicago truncatula roots by Sinorhizobium meliloti. Mol. Plant-Microbe Interact. 12:544-555.

Mirabella, R. 2004. Role of ROP-GTPases and Nod factor signaling in Medicago root nodule infection. Ph.D. thesis, Wageningen University, The Netherlands.

Mitra, R. M., Gleason, C. A., Edwards, A., Hadfield, J., Downie, J. A., Oldroyd, G. E. D., and Long, S. R. 2004. A Ca ${ }^{2+} /$ calmodulin-dependent protein kinase required for symbiotic nodule development: Gene identification by transcript-based cloning. Proc. Natl. Acad. Sci. U.S.A. 101:4701-4705

Navarro-Gochicoa, M. T., Camut, S., Niebel, A., and Cullimore, J. V. 2003a. Expression of the apyrase-like APY1 genes in roots of Medicago truncatula is induced rapidly and transiently by stress and not by $\mathrm{Si}$ norhizobium meliloti or Nod factors. Plant Physiol. 131:1124-1136.

Navarro-Gochicoa, M. T., Camut, S., Timmers, A. C., Niebel, A., Hervé, C., Boutet, E., Bono, J. J., Imberty, A., and Cullimore, J. V. 2003 b. Characterization of four lectin-like receptor kinases expressed in roots of Medicago truncatula: Structure, location, regulation of expression, and potential role in the symbiosis with Sinorhizobium meliloti. Plant Physiol. 133:1893-1910.

Oldroyd, G. E. D., and Downie, J. A. 2004. Calcium, kinases and nodulation signaling in legumes. Nature Rev. 5:566-575.

Oldroyd, G. E. D., and Long, S. R. 2003. Identification and characterization of nodulation-signaling pathway 2, a gene of Medicago truncatula involved in Nod factor signaling. Plant Physiol. 131:1027-1032.

Pichon, M., Journet, E. P., de Billy, F., Dedieu, A., Huguet, T., Truchet, G., and Barker, D. G. 1994. ENOD12 gene expression as a molecular marker for comparing Rhizobium dependent and independent nodulation in alfalfa. Mol Plant-Microbe Interact. 7:740-747.

Pichon, M., Journet, E. P., Dedieu, A., de Billy, F., Truchet, G., and Barker, D. G. 1992. Rhizobium meliloti elicits transient expression of the early nodulin gene ENOD12 in the differentiating root epidermis of transgenic alfalfa. Plant Cell 4:1199-1211.

Quackenbush, J., Cho, J., Lee, D., Liang, F., Holt, I., Karamycheva, S., Parvizi, B., Pertea, G., Sultana, R., and White, J. 2001. The TIGR Gene Indices: Analysis of gene transcript sequences in highly sampled eukaryotic species. Nucleic Acids Res. 29:159-164.

Radutoiu, S., Madsen, L. H., Madsen, E. B., Felle, H. H., Umehara, Y. Gronlund, M., Sato, S., Nakamura, Y., Tabata, S., Sandal, N., and Stougaard, J. 2003 Plant recognition of symbiotic bacteria requires two LysM receptor-like kinases. Nature 425:585-592.

Roche, P., Lerouge, P., Ponthus, C., and Promé, J.C. 1991. Structural determination of bacterial nodulation factors involved in the Rhizobium meliloti-alfalfa symbiosis. J. Biol. Chem. 266:10933-10940.

Schlaman, H. R. M., Phillips, D. A., and Kondorosi, E. 1998. Genetic organization and transcriptional regulation of rhizobial nodulation genes. Pages 361-386 in: The Rhizobiaceae: Molecular Biology of Model Plant-Associated Bacteria. H. P. Spaink, A. Kondorosi, and P. J. J. Hooykaas, eds. Kluwer Academic Publishers, Dordrecht, The Netherlands.

Shaw, S. L., and Long, S. R. 2003. Nod factor inhibition of reactive oxygen efflux in a host legume. Plant Physiol. 132:2196-2204.

Stracke, S., Kistner, C., Yoshida, S., Mulder, L., Sato, S., Kaneko, T., Tabata, S., Sandal, N., Stougaard, J., Szczyglowski, K., and Parniske, M. 2002. A plant receptor-like kinase required for both bacterial and fungal symbiosis. Nature 417:959-962.

Szabados, L., Charrier, B., Kondorosi, A., de Bruijn, F., and Ratet, P. 1995. New plant promoter and enhancer testing vectors. Mol. Breed. 1:419423.

Thoquet, P., Ghérardi, M., Journet, E. P., Kereszt, A., Ané, J. M., Prosperi, J. M., and Huguet, T. 2002. The molecular genetic linkage map of the model legume Medicago truncatula: An essential tool for comparative legume genomics and the isolation of agronomically important genes. BMC Plant Biol. 2:1.

Vasse, J., de Billy, F., Camut, S., and Truchet, G. 1990. Correlation between ultrastructural differentiation of bacteroids and nitrogen fixation in alfalfa nodules. J. Bacteriol. 172:4295-4306.

Vernoud, V., Journet, E. P., and Barker, D. G. 1999. MtENOD20, a Nod factor-inducible molecular marker for root cortical cell activation. Mol. Plant-Microbe Interact. 12:604-614.

Vernoud, V., Pingret, J. L., Chabaud, M., Dedieu, A., de Carvalho Niebel, F., Journet, E. P., and Barker, D. G. 2000. Nod factor signal transduction in the Medicago truncatula nod $^{-} / \mathrm{myc}^{-}$mutants TR25/26. Pages 114-119 in: Biology of Plant-Microbe Interactions, Vol. 2. P. J. G. M. de Witt, T. Bisseling, and W. J. Stiekema, eds. International Society Molecular Plant-Microbe Interactions, St. Paul, MN.

Wagner, E., and Lykke-Andersen, J. 2002. mRNA surveillance: The perfect persist. J. Cell Sci. 115:3033-3038.

Wais, R. J., Galera, C., Oldroyd, G., Catoira, R., Penmetsa, R. V., Cook, D., Gough, C., Dénarié, J., and Long, S. R. 2000. Genetic analysis of calcium spiking responses in nodulation mutants of Medicago truncatula. Proc. Natl. Acad. Sci. U.S.A. 97:13407-13412.

Wais, R. J., Keating, D. H., and Long, S. R. 2002. Structure-function analysis of nod factor-induced root hair calcium spiking in Rhizobiumlegume symbiosis. Plant Physiol. 129:211-224.

Walker, S. A., Viprey, V., and Downie, J. A. 2000. Dissection of nodulation signaling using pea mutants defective for calcium spiking induced by Nod factors and chitin oligomers. Proc. Natl. Acad. Sci. U.S.A. 97:13413-13418. 